\title{
Esophagectomy versus endoscopic resection for patients with early-stage adenocarcinoma: Mercedes versus Tesla
}

\author{
Toni Lerut, MD
}

\author{
From the Department of Thoracic Surgery, University Hospital Leuven, Leuven, Belgium. \\ Disclosures: Author has nothing to disclose with regard to commercial support. \\ Received for publication Dec 10, 2017; accepted for publication Dec 20, 2017; available ahead of print Jan 31, \\ 2017. \\ Address for reprints: Toni Lerut, MD, Department of Thoracic Surgery, University Hospital Leuven, Kortrijkses- \\ traat 191, 3010 Leuven, Belgium (E-mail: toni.lerut@med.kuleuven.be). \\ J Thorac Cardiovasc Surg 2018;155:2209-10 \\ $0022-5223 / \$ 36.00$ \\ Copyright (C) 2018 by The American Association for Thoracic Surgery \\ https://doi.org/10.1016/j.jtcvs.2017.12.104
}

In this issue of the Journal, Marino and colleagues ${ }^{1}$ compare the results of endoscopic resection and esophagectomy for T1a adenocarcinoma. The overall survival curve shows a short-term benefit favoring endoscopic resection, whereas at the end of the day esophagectomy has the better outcome. ${ }^{1}$ This made me involuntarily think of a comparison between a Tesla and a Mercedes.

Tesla (endoscopic resection) stands for new technology, cool and hip, and Mercedes (esophagectomy) has been the symbol of technical perfection and sustainability for decades. Tesla accelerates from 1 to 60 miles per hour in 1.6 seconds, outperforming the Mercedes (= better shortterm outcome), but the Mercedes has a longer range (= better long-term outcome).

The retrospective nature of the study and a number of missing data in the National Cancer Database are, as acknowledged by the authors, limitations that do not allow for a clear conclusion on which treatment is to be preferred for earlystage (T1a) esophageal carcinoma. However, the study is relevant because it uncovers some important features.

By analyzing the short-term (ie, up to 90 days) survival, there is a clear advantage with endoscopic resection. An advantage is related to the significantly higher postoperative mortality after esophagectomy, $4.3 \%$ versus $0.5 \%$. This is a crucial figure. Indeed, can we as surgeons afford to have an approximately 9-fold higher mortality risk for a condition that may offer a near $100 \%$ oncologic cure rate?

The introduction of minimally invasive esophagectomy technology has resulted in a substantial decrease of postoperative morbidity, and emerging fast-track (Enhanced Recovery After Surgery) protocols are reducing the length of hospital stay, making esophagectomy more competitive with nonsurgical therapies, however, only provided a near zero postoperative mortality.

This raises the obvious question, who should operate on these patients and in which institutions? The answer is suggested by the multivariable analysis in the matched group: only well-trained and experienced surgeons in highvolume hospitals.

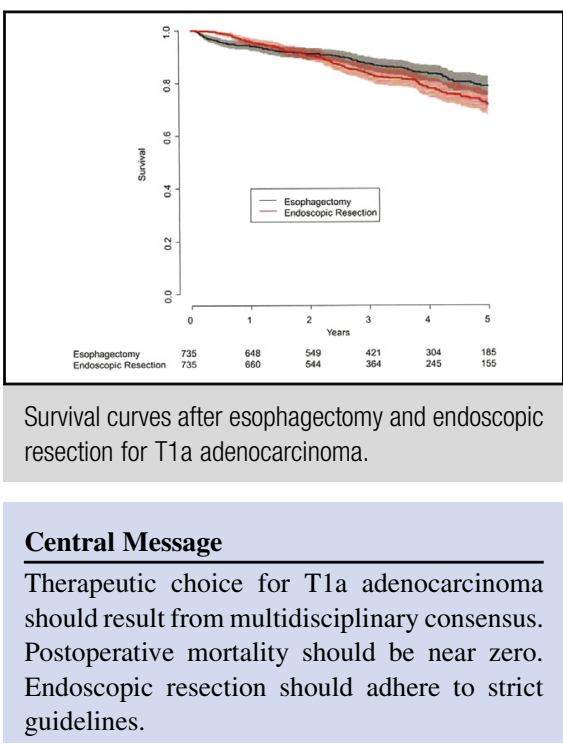

See Article page 2211.

The second part of the survival curve, the long-term outcome, favors esophagectomy. The lack of data on the National Cancer database allows only for speculation to explain this. Obviously, esophagectomy combined with extensive lymphadenectomy allows for complete removal of all cancerous tissue, potentially offering better chances for survival. ${ }^{2}$

Another important prognosticator is the quality of the endoscopic resection. Piecemeal resection has to be avoided. After endoscopic resection of the tumor, residual Barrett tissue (if present) needs to be ablated as well. ${ }^{3,4}$

As shown in a recent study by the same authors of the actual study, querying the same National Cancer database, lesions of $25 \mathrm{~mm}$ or more (13\% of T1a lesions) carry a higher risk ( 2 points in the proposed risk score system) of lymph node involvement. ${ }^{5}$ A removal of such a subgroup in the actual study may show an equal if not better longterm survival compared with surgery. For endoscopic resection, adherence to well-established guidelines ${ }^{4}$ combined with oncologic risk assessment ${ }^{5}$ is the key for optimal outcomes.

Given the specificities of each patient presenting with a T1a adenocarcinoma and the available treatment modalities, the best guarantee for an optimal therapeutic decision can be obtained only through consensus after a multidisciplinary collaborative discussion. 


\section{References}

1. Marino KA, Sullivan JL, Weksler B. Esophagectomy versus endoscopic resection for patients with early-stage adenocarcinoma: a National Cancer Database propensity-matched study. J Thorac Cardiovasc Surg. 2018;155:2211-8.e1.

2. Ajani JA, Barthel JS, Bentrem DJ, D’Amico TA, Das P, Denlinger CS, et al. National Comprehensive Cancer Network. Esophageal and esophagogastric junction cancers. J Natl Compr Canc Netw. 2011;9:830-87.

3. Pimentel-Nunes P, Dinis-Ribeiro M, Ponchon T, Repici A, Vieth M, De Ceglie A, et al. Endoscopic submucosal dissection: European Society of
Gastrointestinal Endoscopy (ESGE) Guideline. Endoscopy. 2015;47: 829-54.

4. Manner H, May A, Pech O, Gossner L, Rabenstein T, Günter E, et al. Early Barrett's carcinoma with "low-risk" submucosal invasion: long-term results of endoscopic resection with a curative intent. Am J Gastroenterol. 2008;103: 2589-97.

5. Weksler B, Kennedy KF, Sullivan JL. Using the National Cancer Database to create a scoring system that identifies patients with early-stage esophageal cancer at risk for nodal metastases. J Thorac Cardiovasc Surg. 2017; 154:1787-93. 